\title{
Article \\ Effects of Different Air Particle Abrasion Protocols on the Biaxial Flexural Strength and Fractography of High/Ultra-Translucent Zirconia
}

\author{
Reem AlMutairi *, Hend AlNahedh (D), Ahmed Maawadh and Ahmed Elhejazi (D) \\ Department of Restorative Dental Sciences, College of Dentistry, King Saud University, P.O. Box 93504, \\ Riyadh 11683, Saudi Arabia; HAlNahedh@ksu.edu.sa (H.A.); amaawadh@ksu.edu.sa (A.M.); \\ ahmed.hejazi@gmail.com (A.E.) \\ * Correspondence: reemalmutairi.993@gmail.com
}

check for updates

Citation: AlMutairi, R.; AlNahedh, H.; Maawadh, A.; Elhejazi, A. Effects of Different Air Particle Abrasion Protocols on the Biaxial Flexural Strength and Fractography of High/Ultra-Translucent Zirconia. Materials 2022, 15, 244. https://doi.org/10.3390/ ma15010244

Academic Editor: Jung-Suk Han

Received: 23 November 2021

Accepted: 28 December 2021

Published: 29 December 2021

Publisher's Note: MDPI stays neutral with regard to jurisdictional claims in published maps and institutional affiliations.

Copyright: (C) 2021 by the authors. Licensee MDPI, Basel, Switzerland. This article is an open access article distributed under the terms and conditions of the Creative Commons Attribution (CC BY) license (https:/ / creativecommons.org/licenses/by/ $4.0 /)$.

\begin{abstract}
In this study, the biaxial flexural strength (BFS) and fractography of high/ultra-translucent monolithic zirconia ceramics subjected to different mechanical surface pretreatments were evaluated. A total of 108 disc-shaped samples (12 mm diameter, $1.2 \mathrm{~mm}$ thickness) of three zirconia materials (5Y-ZP KATANA Zirconia UTML (ML), 3Y-TZP DD Bio ZX2 (DB), and 5Y-ZP DD cube $\mathrm{X} 2$ (DC)) were used. The BFS was investigated after subjecting the samples to surface treatment using air abrasion particles of two types (aluminum oxide or glass microbeads). The data were analyzed using two-way analysis of variance, followed by Scheffe's post hoc test for multiple comparisons. The mean \pm standard deviation $\mathrm{BFS}$ for $\mathrm{DB}$ was highest after treatment with $50 \mu \mathrm{m} \mathrm{Al}_{2} \mathrm{O}_{3}$ $(1626.05 \pm 31.9 \mathrm{MPa})$, with lower values being observed following treatment with $50 \mu \mathrm{m}$ glass microbeads (1399.53 $\pm 24.2 \mathrm{MPa})$ and in the control sample (1198.51 $\pm 21.1 \mathrm{MPa})$. The mean \pm standard deviation (SD) BFSs for DC and ML were the highest in the control groups. Surface air abrasion with $50 \mu \mathrm{m} \mathrm{Al}{ }_{2} \mathrm{O}_{3}$ particles and 2 bar pressure is recommended for $3 \mathrm{Y}-\mathrm{TZP}$ translucent zirconia, while no abrasion of $5 \mathrm{Y}-\mathrm{ZP}$ translucent zirconia ceramic.
\end{abstract}

Keywords: airborne particle abrasion; biaxial flexural strength; fractography; high translucent zirconia

\section{Introduction}

All-ceramic-based dental restorations are of particular importance due to their superior biocompatibility and aesthetics compared to porcelain fused to metal restorations [1]. More specifically, $3 \mathrm{~mol} \%$ yttria-stabilized tetragonal zirconia polycrystalline (3Y-TZP) has become one of the main substitutes for metal ceramic restorations because of its high flexural strength and fracture toughness, in addition to its low enamel and material wear [2]. However, zirconia exhibits a lower translucency and a high opacity compared to lithium disilicate ceramics, thereby resulting in inferior aesthetics [3].

To improve the material translucency and overcome this shortcoming, newer generations of zirconia with higher translucency parameters have been developed. More specifically, first-generation materials consisted of 3Y-TZP and contained $0.25 \mathrm{wt} \%$ alumina $\left(\mathrm{Al}_{2} \mathrm{O}_{3}\right)$ [4]. Although the strength and fracture toughness of this generation of materials were higher than those of newer generations, they exhibited a high opacity due to the presence of tetragonal zirconia phases, which resulted in light scattering from the grain boundaries, additive inclusions, and pores [4]. This type of zirconia is therefore recommended for the fabrication of framework materials in fixed partial dentures and porcelain-layered crowns. The second generation of 3Y-TZP materials was characterized by a reduced porosity that was achieved using a higher firing temperature and by reducing the amount of alumina within the material $[5,6]$. Such improvements resulted in a 3Y-TZP material with a higher translucency, which is otherwise known as highly translucent zirconia. Although the second 
generation of 3Y-TZP materials showed an improved translucency, their aesthetics were insufficient for use as monolithic ceramic restorations in the anterior aesthetic zone [4].

Subsequently, third generation materials were developed using an yttria content of $5 \mathrm{~mol} \%$ (5Y-ZP), which is referred to by manufacturers as ultra-translucent (or super-hightranslucent) zirconia, while fourth generation materials were based on zirconia with an yttria content of $4 \mathrm{~mol} \%$ (4Y-ZP), which exhibited enhanced mechanical properties [7]. Both the third and fourth generation materials contained increased amounts of the cubic phase, which imparted the material with its superior translucency [4]. Such materials therefore become suitable for use in the fabrication of anterior crowns and fixed partial dentures [4]. Due to the increased amounts of the cubic phase present in the newer generation materials, stressinduced transformations do not take place, ultimately resulting in a marked decrease in their strength and fracture toughness properties [8-10]. Bonding of zirconia to tooth structure presents a clinical problem as zirconia cannot be etched with acids as in glass-based systems. A previous meta-analysis reported that a combination of mechanical and chemical surface pre-treatment processes is essential to obtain durable bonding to zirconia [11].

To alter the internal surface of zirconia and increase both its mechanical retention and its bonding to the resin cement, air abrasion is commonly employed [12] using airborne particles such as aluminum oxide [13]. The air abrasion of 3Y-TZP results in the formation of a compressive layer that acts as a protective surface, and this can be attributed to a transformation toughening from the tetragonal to the monoclinic phase [14]. Moreover, it leads to the formation of surface flaws that limit the strength owing to crack propagation [14]. A further study reported that the use of an air particle abrasion pressure of $0.2 \mathrm{MPa}$ for this process resulted in a more stable and reliable bond strength between the resin cement and three zirconia materials with varying translucency values [15].

However, the effect of air particle abrasion on the flexural strength of 3Y-TZP zirconia is controversial, since it depends on the size of the abrading particles, their type, and the air pressure employed [12]. For example, some studies have reported an increased flexural strength after air particle abrasion, and this could be accounted for by considering that the transformation toughening mechanism counterbalances any potential critical defect introduced by airborne particle abrasion [16-20]. In contrast, other works have reported a decreased strength after air particle abrasion owing to the introduction of large surface flaws [21-23].

Currently, limited evidence is available regarding the use of low abrasive particles and low air pressures when treating high-translucent zirconia [24]. Air abrasion on tooth enamel, dentin, and nickel-chromium alloys with glass beads is commonly used [25,26], which results in low bond strength values for nickel-chromium alloys when compared with aluminum oxide treatment [25]. In addition, air abrasion with glass beads has been found to decrease the bonding strengths of materials to enamel and dentin, whereas air abrasion with alumina decreased the adhesion to enamel but not to dentin [26]. Due to the fact that glass beads are softer than alumina particles, they could be considered an alternative surface treatment for high-translucent zirconia [27].

To date, the effects of different air particle abrasion protocols on the flexural strength of highly translucent zirconia have yet to be examined in detail. The aim of this study is therefore to evaluate the biaxial flexural strength (BFS) values and carry out a qualitative fractographic analysis of high-translucent and ultra-translucent monolithic zirconia ceramics subjected to different mechanical surface treatment protocols. Two null hypotheses are tested: (1) the biaxial flexural strengths of high-translucent and ultra-translucent zirconia ceramics are not affected by air abrasion surface treatment with $50 \mu \mathrm{m}$ aluminum oxide particles, and (2) the BFSs of high-translucent zirconia and ultra-translucent zirconia ceramics are not affected by air abrasion surface treatment with $50 \mu \mathrm{m}$ glass microbead particles. 


\section{Materials and Methods}

\subsection{Preparation of the Samples}

Table 1 lists the various materials employed in this study along with their compositions and commercial sources.

Table 1. Materials employed during this study.

\begin{tabular}{|c|c|c|c|c|}
\hline Material & Brand Name & Shade & Composition & Manufacturer \\
\hline $\begin{array}{l}\text { High-translucent } \\
\text { 3Y-TZP ceramic }\end{array}$ & DD Bio ZX2 & White & $\begin{array}{l}\geq 99 \% \mathrm{ZrO}_{2}+\mathrm{HfO}_{2}+\mathrm{Y}_{2} \mathrm{O}_{3} \\
<6 \% \mathrm{Y}_{2} \mathrm{O}_{3}, \leq 0.15 \% \mathrm{Al}_{2} \mathrm{O}_{3} \\
\quad<1.0 \% \text { other oxides. }\end{array}$ & $\begin{array}{c}\text { Dental Direkt Materials, } \\
\text { Germany }\end{array}$ \\
\hline $\begin{array}{l}\text { Superhigh-translucent } \\
\text { 5Y-TZP ceramic }\end{array}$ & DD Cube X2 & White & $\begin{array}{l}\geq 99 \% \mathrm{ZrO}_{2}+\mathrm{HfO}_{2}+\mathrm{Y}_{2} \mathrm{O}_{3} \\
<10 \% \mathrm{Y}_{2} \mathrm{O}_{3}, \leq 0.01 \% \mathrm{Al}_{2} \mathrm{O}_{3} \\
\quad<1.0 \% \text { other oxides. }\end{array}$ & $\begin{array}{c}\text { Dental Direkt Materials, } \\
\text { Germany }\end{array}$ \\
\hline $\begin{array}{l}\text { Ultra-translucent } \\
\text { 5Y-ZP ceramic }\end{array}$ & KATANA zirconia UTML & White & $\begin{array}{l}87-92 \% \mathrm{ZrO}_{2}, 8-11 \% \mathrm{Y}_{2} \mathrm{O}_{3} \\
<2 \% \text { other oxides. }\end{array}$ & $\begin{array}{c}\text { Kuraray Noritake } \\
\text { Dental, Tokyo, Japan }\end{array}$ \\
\hline $\begin{array}{l}50 \mu \mathrm{m} \text { glass } \\
\text { microbead particles }\end{array}$ & Rolloblast & & Glass microbeads & Renfert, Germany \\
\hline $\begin{array}{l}50 \mu \mathrm{m} \text { aluminum } \\
\text { oxide particles }\end{array}$ & Cobra & & Aluminum oxide & Renfert, Germany \\
\hline
\end{tabular}

A total of 108 zirconia discs (15 mm diameter, $1.5 \mathrm{~mm}$ thickness) were prepared from pre-sintered zirconia blocks (KATANA Zirconia UTML, Kuraray Noritake Dental, Tokyo, Japan; DD Bio ZX2, Dental Direkt Materials, Germany; and DD Cube X2, Dental Direkt Materials, Germany) using computer-aided design and computer-aided-manufacture techniques (DWOS, Dental Wings, Montreal, QC, Canada) [28]. The sintering of all samples was performed according to the manufacturer's recommendations, as outlined in Table 2. Both sides of each sample were polished with 600 and 1200 grit silicon carbide paper under wet conditions for $15 \mathrm{~s}$ [15]. The samples were ultrasonically cleaned in distilled water for $10 \mathrm{~min}$ and then air-dried prior to surface treatment. The samples were subsequently divided into nine subgroups ( $n=12$ per group) according to the surface treatment employed (Figure 1 ). More specifically, the control group underwent no surface treatment; the DB1, DC1, and ML1 subgroups were subjected to air abrasion with $50 \mu \mathrm{m}$ aluminum oxide particles; and the DB2, DC2, and ML2 groups were subjected to air abrasion with $50 \mu \mathrm{m}$ glass microbeads.

Table 2. Sintering conditions for preparation of the different zirconia materials.

\begin{tabular}{ccc}
\hline Material (Brand Name) & Sintering Temperature & Holding Time \\
\hline DD Bio ZX2 & $1450{ }^{\circ} \mathrm{C}$ & $9 \mathrm{~h}$ \\
DD Cube X2 & $1450{ }^{\circ} \mathrm{C}$ & $9 \mathrm{~h}$ \\
KATANA zirconia UTML & $1550{ }^{\circ} \mathrm{C}$ & $2 \mathrm{~h}$ \\
\hline
\end{tabular}

Each air abrasion procedure was performed under a standardized pressure of 2 bar with a nozzle placed at a $90^{\circ}$ incidence angle from the center of the sample. The nozzle was placed at a distance of $10 \mathrm{~mm}$ and air abrasion was carried out for $20 \mathrm{~s}$ using a sandblaster (Duostar Plus, BEGO, Germany) [15,29,30]. 


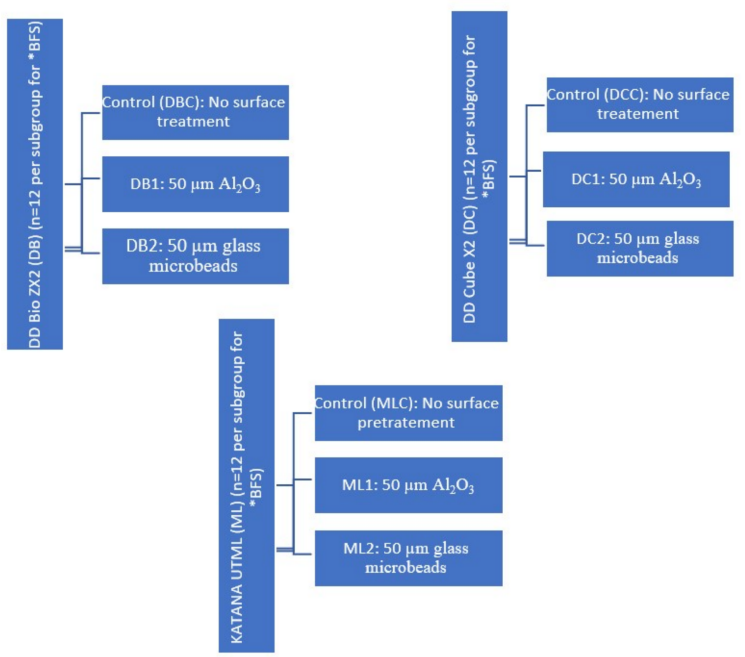

Figure 1. Schematic representation of the different ceramic material groups to be subjected to surface pre-treatment with different types of air abrasion particles. These specimens were then employed in the biaxial flexural strength test. * DB: DD Bio ZX2 ceramic material, DC: DD Cube X2 ceramic material, ML: KATANA UTML ceramic material, BFS: biaxial flexural strength.

\subsection{Biaxial Flexural Strength (BFS)}

A total of 108 samples were ultrasonically cleaned with $99 \%$ isopropanol for $180 \mathrm{~s}$, air-dried, and subjected to biaxial flexural strength testing according to ISO 6872 [31]. The samples were placed on three steel balls measuring $3.2 \mathrm{~mm}$ in diameter, which were in turn placed on a $10 \mathrm{~mm}$ diameter support circle with an angle of $120^{\circ}$ between the steel balls. A mechanical testing machine (Type 5567, Instron, Canton, MA, USA) was employed to impart a $5 \mathrm{kN}$ load onto the sample with a crosshead speed of $0.5 \mathrm{~mm} / \mathrm{min}$ until sample fracture occurred. The load was applied using a piston-shaped indenter with a diameter of $1.2 \mathrm{~mm}$, and the load was directed to the center of the sample. The BFS was measured according to ISO $6872[28,30,31]$ and was calculated as follows:

$$
\begin{gathered}
S=-0.2387 P(X-Y) / d^{2} \\
X=(1+v) \operatorname{In}\left(r_{2} / r_{3}\right)^{2}+([1-v] / 2)\left(r_{2} / r_{3}\right)^{2} \\
Y=(1+v)\left(1+\operatorname{In}\left[r_{1} / r_{3}\right]^{2}\right)+(1-v)\left(r_{1} / r_{3}\right)^{2}
\end{gathered}
$$

where $S$ is the BFS (MPa), $P$ is the fracture load $(N), d$ is the disc specimen thickness at the fracture site $(\mathrm{mm}), \mathrm{v}$ is Poisson's ratio $(0.25), \mathrm{r}_{1}$ is the radius of the support circle $(5 \mathrm{~mm})$, $r_{2}$ is the radius of the loaded area $(0.6 \mathrm{~mm})$, and $r_{3}$ is the radius of the specimen $(6 \mathrm{~mm})$.

\subsection{Fractographic Analysis}

The fractured surfaces were ultrasonically cleaned for $10 \mathrm{~min}$ using distilled water, then air-dried and examined using a digital microscope (DIGITAL MICROSCOPE KH-7700, Hirox, Tokyo, Japan) for determination of the fracture origin in relation to the fractography principles of ceramics [32]. The selected representative fractured samples were evaluated by scanning electron microscopy (JSM-6360LV, JEOL Ltd., Tokyo, Japan) with magnification ranges from $50 \times$ to $400 \times$. The samples were coated with a thin coating of gold via ion sputtering (JFC-1100, JEOL Ltd., Tokyo, Japan). The fracture origins were determined on the fracture surface by recognizing specific fracture patterns, tracing back to the fracture origin sites, and examining the progression of fracture. A number of fracture patterns were identified in the descriptive fractographic analysis of fractured zirconia samples, including hackles, twist hackles, arrest lines, compression curls, and void defects [33]. 


\subsection{Statistical Analysis}

Data were collected and grouped for statistical analysis using a statistical software package (SPSS version 23). Statistical analysis was performed using the Shapiro-Wilk test of normal distribution $(p>0.05)$. Two-way analysis of variance (ANOVA) was conducted to evaluate the null hypothesis, followed by Scheffe's post hoc tests for multiple comparisons $(p<0.05)$. The level of significance was set at $p \leq 0.05$.

\section{Results}

\subsection{Biaxial Flexural Strength (BFS) Testing}

Two-way ANOVA showed a statistically significant difference in the BFS between the various surface pre-treatment groups $(p<0.05)$, and the interaction effect between the ceramic material group and the surface pre-treatment group was also found to be statistically significant $(p<0.05)$. In addition, one-way ANOVA showed a statistically significant difference between the BFS values of the surface pre-treatment groups for all ceramic materials $(p<0.05)$ (Table 3$)$.

Table 3. Mean (and SD) biaxial flexural strengths (MPa) of the various experimental groups.

\begin{tabular}{|c|c|c|c|c|c|c|c|c|c|}
\hline & & \multirow{2}{*}{ Mean } & \multirow{2}{*}{$\begin{array}{l}\text { Standard } \\
\text { Deviation }\end{array}$} & \multirow{2}{*}{$\begin{array}{l}\text { Standard } \\
\text { Error }\end{array}$} & \multicolumn{2}{|c|}{ 95\% Confidence Interval for Mean } & \multirow{2}{*}{ Min } & \multirow{2}{*}{ Max } & \multirow{2}{*}{$p$ Value } \\
\hline & & & & & Lower Bound & Upper Bound & & & \\
\hline \multirow{3}{*}{ DD Bio ZX2 (DB) } & Control & $1198.52^{c}$ & 21.20 & 6.12 & 1185.05 & 1211.98 & 1162.09 & 1225.26 & \multirow{3}{*}{$0.000 *$} \\
\hline & $50 \mu \mathrm{m} \mathrm{Al} \mathrm{O}_{3}$ & $1626.06^{a}$ & 31.94 & 9.22 & 1605.76 & 1646.35 & 1588.83 & 1676.23 & \\
\hline & $50 \mu \mathrm{m}$ glass microbeads & $1399.53^{b}$ & 24.25 & 7.00 & 1384.12 & 1414.94 & 1346.51 & 1439.88 & \\
\hline \multirow{3}{*}{ DD Cube X2 (DC) } & Control & $856.73^{a}$ & 26.89 & 7.76 & 839.64 & 873.82 & 800.96 & 923.32 & \multirow{3}{*}{0.000 * } \\
\hline & $50 \mu \mathrm{m} \mathrm{Al} \mathrm{O}_{3}$ & $490.40^{c}$ & 6.96 & 2.01 & 485.98 & 494.83 & 477.24 & 501.06 & \\
\hline & $50 \mu \mathrm{m}$ glass microbeads & $712.64^{b}$ & 19.38 & 5.59 & 700.32 & 724.95 & 687.15 & 740.27 & \\
\hline \multirow{3}{*}{ KATANA UTML (ML) } & Control & $761.91^{a}$ & 19.44 & 5.61 & 749.55 & 774.26 & 728.21 & 789.29 & \multirow{3}{*}{0.000 * } \\
\hline & $50 \mu \mathrm{m} \mathrm{Al} \mathrm{O}_{3}$ & $437.92^{c}$ & 29.57 & 8.54 & 419.12 & 456.71 & 396.21 & 487.36 & \\
\hline & $50 \mu \mathrm{m}$ glass microbeads & $711.76^{b}$ & 10.39 & 3.00 & 705.16 & 718.36 & 694.05 & 730.08 & \\
\hline
\end{tabular}

* Statistically significant at $p \leq 0.05 .{ }^{*}$ Different small letters indicate significant differences at $p \leq 0.05$.

The mean \pm SD BFS for the DD Bio ZX2 (DB) sample reached its highest value after treatment with $50 \mu \mathrm{m} \mathrm{Al}_{2} \mathrm{O}_{3}$, with a lower value being obtained following treatment with $50 \mu \mathrm{m}$ glass microbeads, and the lowest value being observed for the control. In contrast, the mean \pm SD BFSs for the DC and ML samples reached their highest values in the control and became lower after treatment with the $50 \mu \mathrm{m}$ glass microbeads and the $50 \mu \mathrm{m} \mathrm{Al}_{2} \mathrm{O}_{3}$ particles (Figure 2).

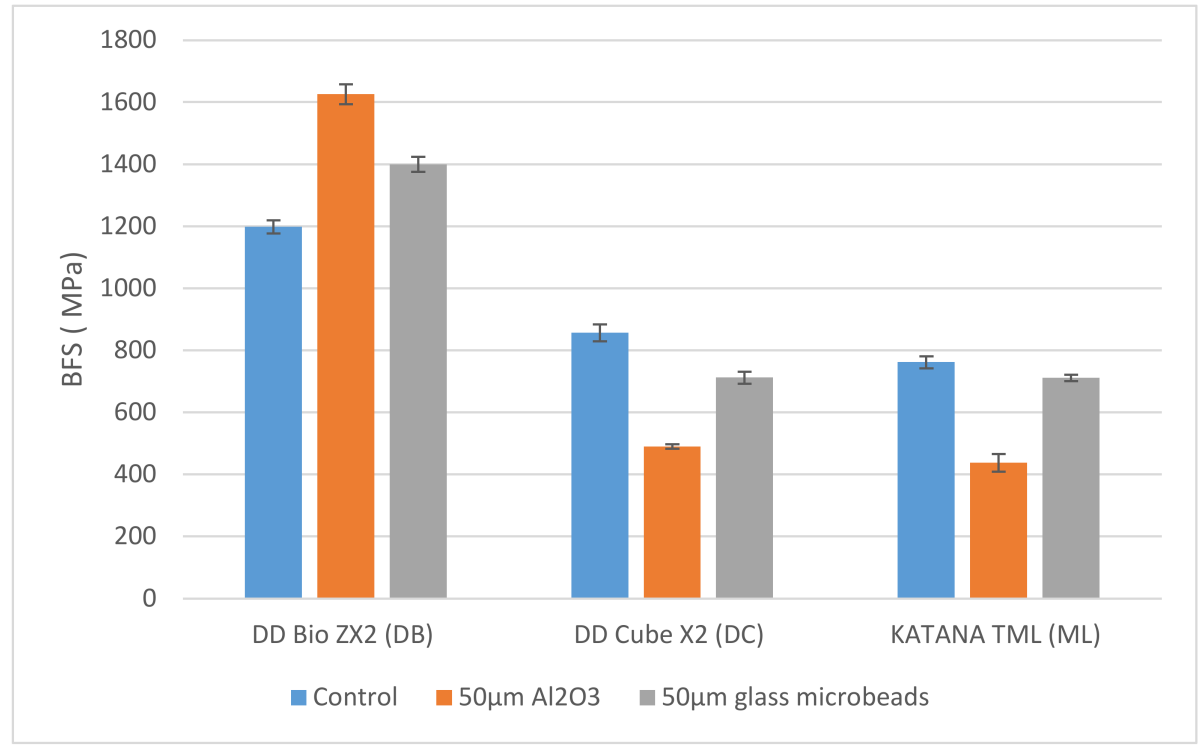

Figure 2. Mean biaxial flexural strengths (MPa) of the various experimental groups. 
Scheffe's post hoc test showed that for the DB, DC, and ML materials, statistically significant differences were present in the BFS values between the various sample groups $(p<0.05)$. More specifically, for the DB samples, the mean \pm SD BFS after treatment with $50 \mu \mathrm{m} \mathrm{Al}{ }_{2} \mathrm{O}_{3}$ was significantly higher than the control sample and after treatment with the $50 \mu \mathrm{m}$ glass microbeads $(p<0.05)$. In contrast, both the DC and ML samples showed mean \pm SD BFS values that were statistically significantly higher in the control group than after treatment with either the $50 \mu \mathrm{m} \mathrm{Al}{ }_{2} \mathrm{O}_{3}$ beads or the $50 \mu \mathrm{m}$ glass microbeads $(p<0.05)$ (Table 4).

Table 4. Scheffe's post hoc test for the BFS (MPa).

\begin{tabular}{|c|c|c|c|c|c|c|c|}
\hline & & \multicolumn{2}{|c|}{ DD Bio ZX2 (DB) } & \multicolumn{2}{|c|}{ DD Cube X2 (DC) } & \multicolumn{2}{|c|}{ KATANA UTML (ML) } \\
\hline & & Mean Difference & $p$ Value & Mean Difference & $p$ Value & Mean Difference & $p$ Value \\
\hline \multirow{2}{*}{$50 \mu \mathrm{m} \mathrm{Al}_{2} \mathrm{O}_{3}$} & $50 \mu \mathrm{m}$ glass microbeads & $226.5240 *$ & 0.000 & $-222.2337 *$ & 0.000 & $-273.8480 *$ & 0.000 \\
\hline & Control & $427.5403 *$ & 0.000 & $-366.3253 *$ & 0.000 & $-323.9907^{*}$ & 0.000 \\
\hline $50 \mu \mathrm{m}$ glass microbeads & Control & 201.0163 * & 0.000 & $-144.0916^{*}$ & 0.000 & $-50.1427^{*}$ & 0.000 \\
\hline
\end{tabular}

* Statistically significant at $p \leq 0.05$.

\subsection{Fractographic Analysis}

Significant differences in the topography of the abraded ceramic surfaces in comparison with control can be seen (Figure 3). The use of $50 \mu \mathrm{m} \mathrm{Al}_{2} \mathrm{O}_{3}$ particles resulted in the generation of rougher surfaces, while for the groups treated with $50 \mu \mathrm{m}$ glass microbeads, pitting of the surface was observed in all cases. The various fractured discs obtained following surface treatment of the samples are shown in Figure 4. Compared to the sintered control group, it can be seen that the airborne particle-abraded DB samples shattered into multiple fragments of varying sizes, while fewer fragments were obtained for the airborne particle-abraded DC and ML samples.

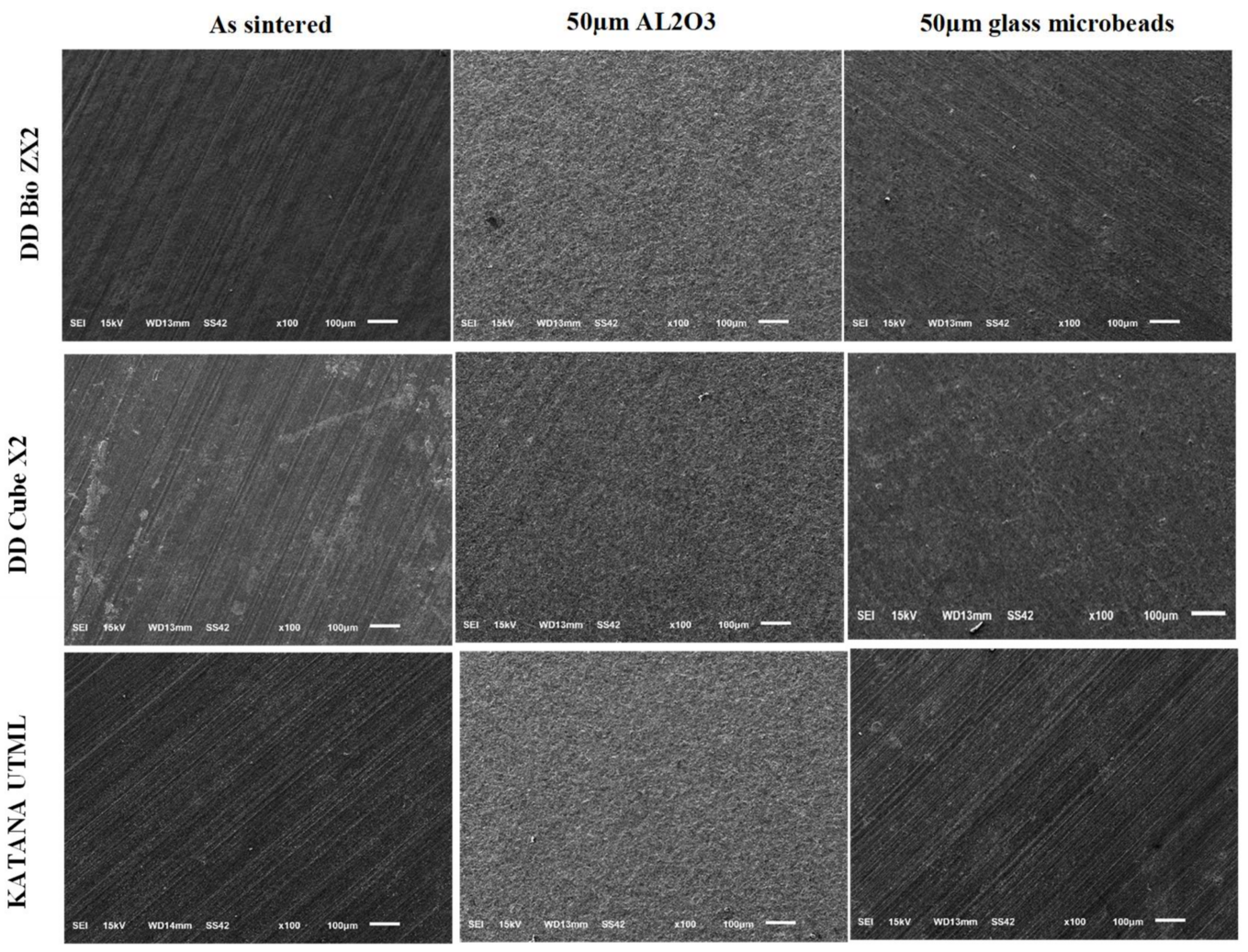

Figure 3. Representative SEM images showing the effects of abrasion using $50 \mu \mathrm{m}$ aluminum oxide particles and $50 \mu \mathrm{m}$ glass microbeads on the surfaces of different zirconia ceramics. 
As sintered
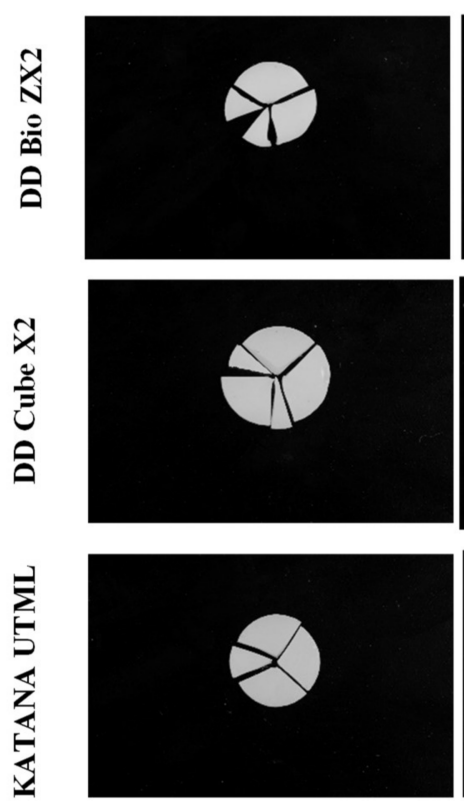

50 $\mu$ m AL2O3
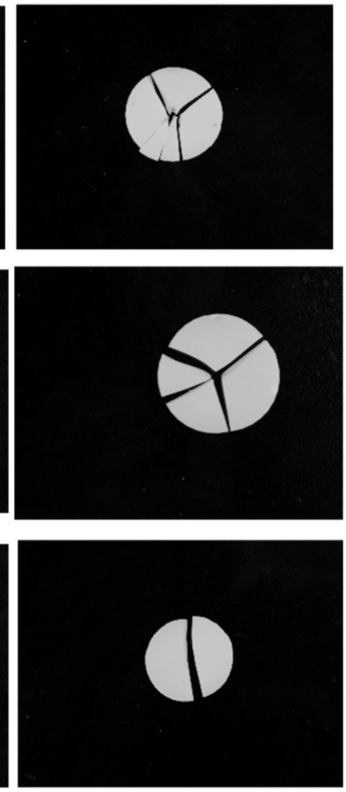

$50 \mu m$ glass microbeads
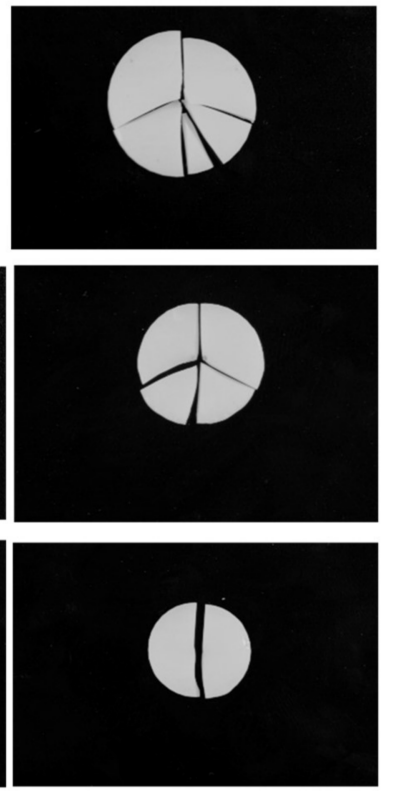

Figure 4. Representative fractured discs for the different zirconia groups.

SEM examinations revealed numerous characteristic features for the fractured zirconia ceramic surfaces, wherein the fracture origins $\left({ }^{*}\right)$, direction of crack propagation (dotted arrows), secondary cracks, hackles, river delta, arrest lines, and compression curls were clearly evident (Figures 5-7). Twist hackles formed when the principal tension axis undergoes a lateral rotation and the crack twists (Figure $5 \mathrm{c}$ ). As the crack approaches the compression side of the sample, the crack slows down to leave a curved lip (compression curl) just before the total fracture of the material indicating the end of the fracture (Figure $5 \mathrm{~d}$, Figure $6 \mathrm{c}$, and Figure 7d). An arrest line can also be observed (black arrow), indicating a change in direction of the crack propagation (Figure 5h). The DB sample tended to exhibit a smoother fractured surface than the other tested zirconia materials, although multiple secondary cracks were also present, which led to the generation of smaller ceramic fragments (Figure 5). For the DC sample, cracks began to appear at areas that exhibited surface and subsurface porosity, wherein the cracks progressed in multiple planes (Figure 6b), and secondary cracks were frequently observed in the fractured specimens (Figure 6). Furthermore, for the ML sample, clear fracture lines and smooth fracture surfaces were observed (Figure 7).
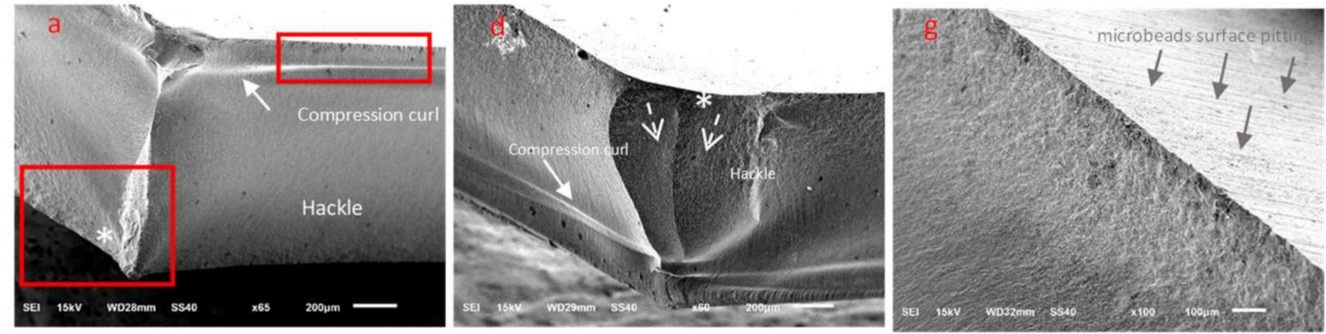

Figure 5. Cont. 

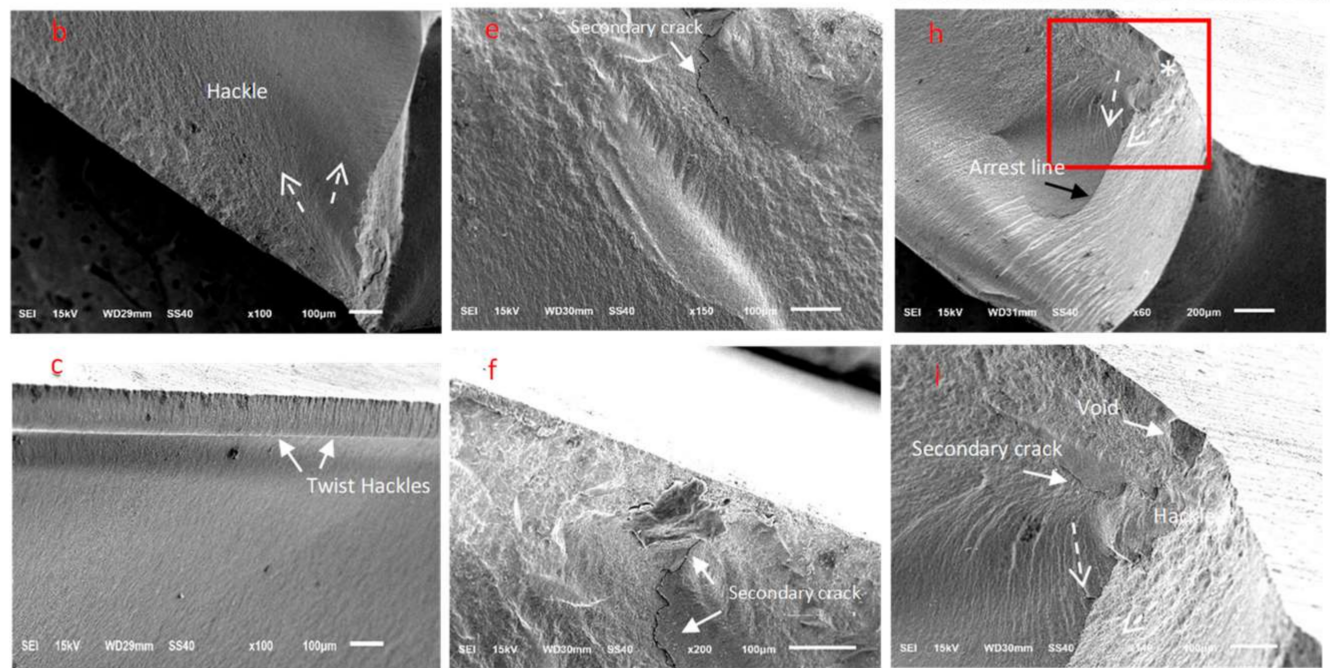

Figure 5. Representative SEM images of the ceramic DB fractured discs. (a-c) The control as sintered group, $(\mathbf{d}-\mathbf{f})$ the $50 \mu \mathrm{m} \mathrm{Al} \mathrm{O}_{3}$-treated group, and $(\mathrm{g}-\mathbf{i})$ the $50 \mu \mathrm{m}$ glass microbead-treated group.
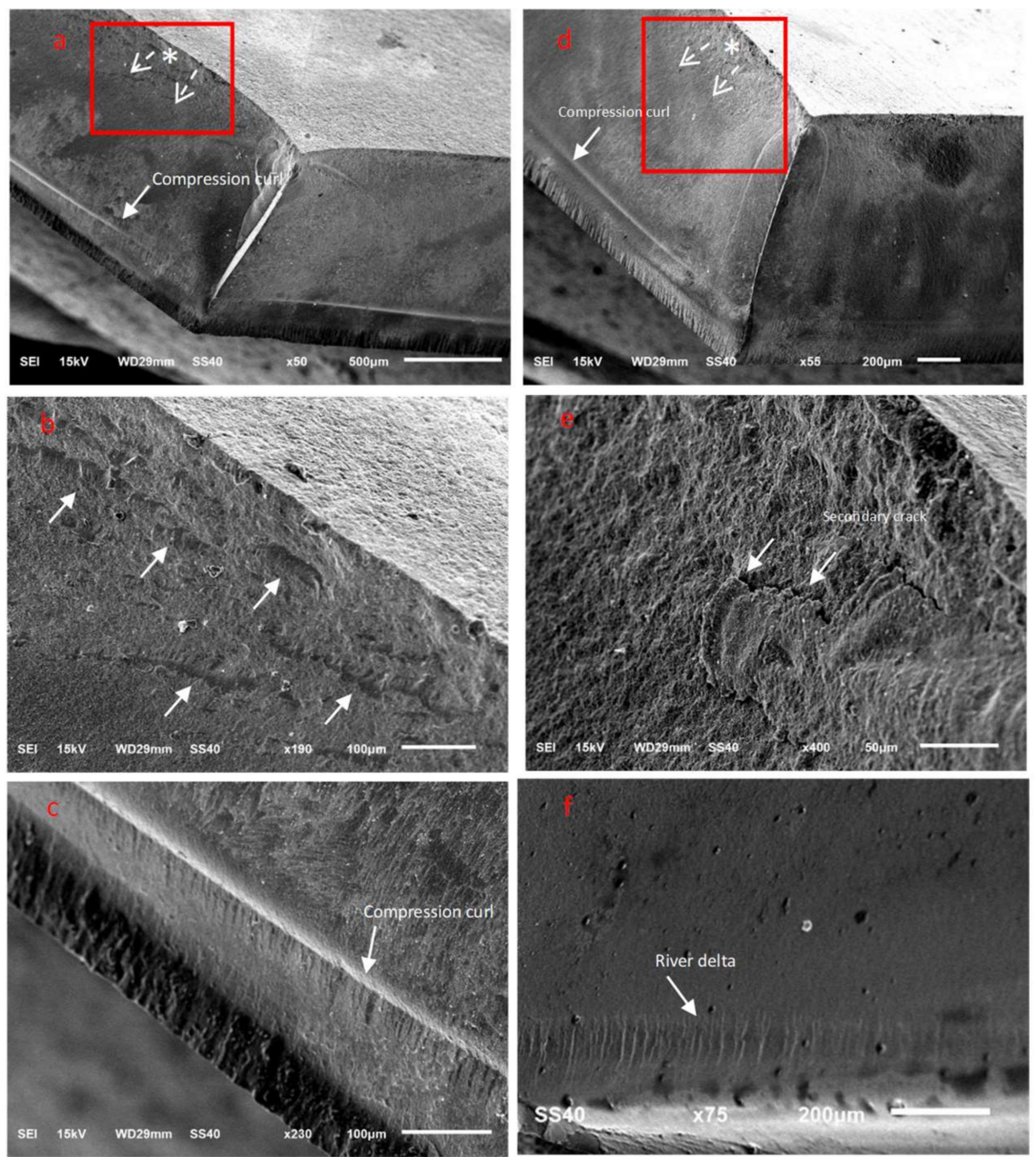

Figure 6. Representative SEM images of the ceramic DC fractured discs. (a-c) The $50 \mu \mathrm{m} \mathrm{Al}_{2} \mathrm{O}_{3}$ treated group, and $(\mathbf{d}-\mathbf{f})$ the $50 \mu \mathrm{m}$ glass microbead-treated group. 

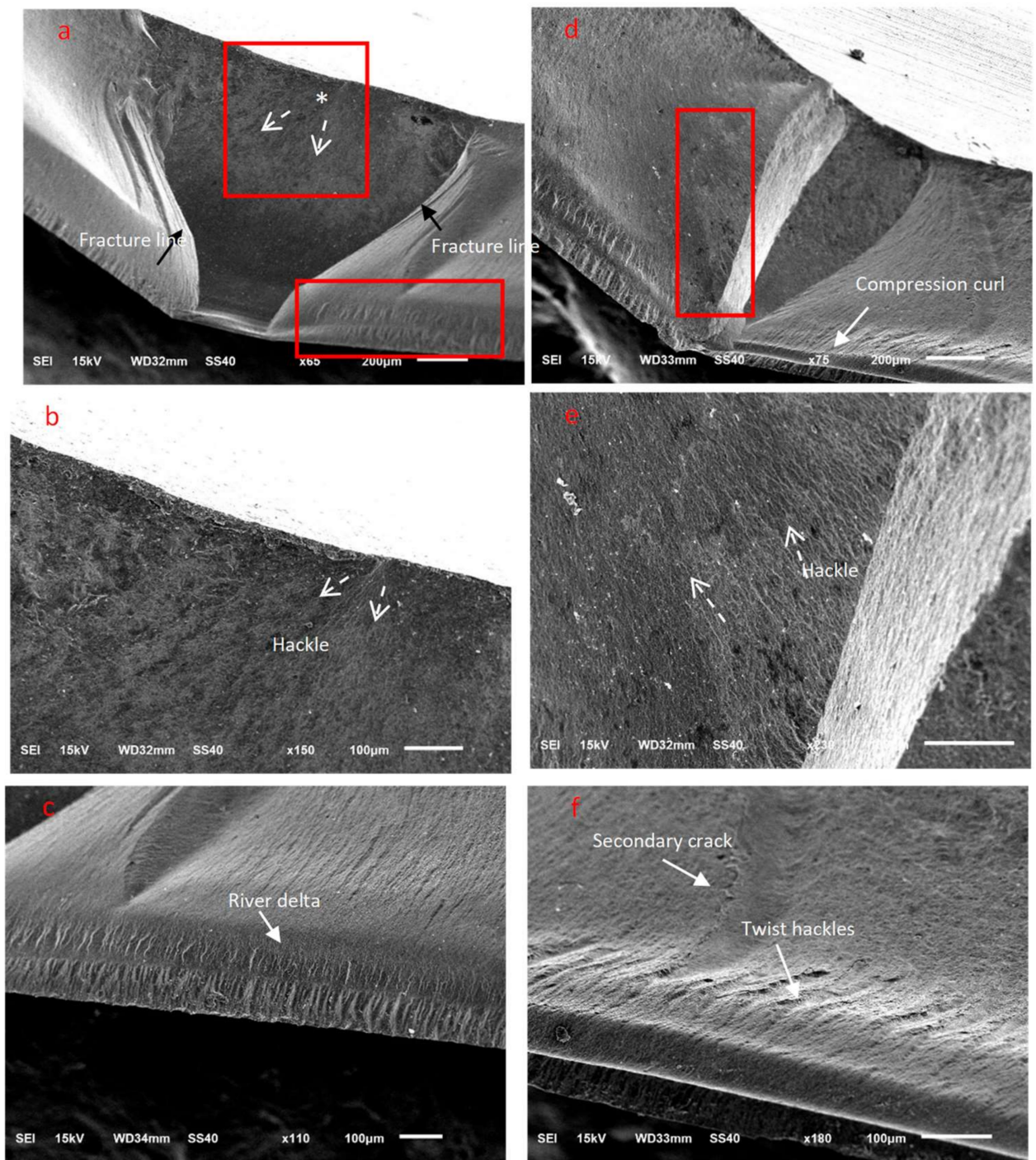

Figure 7. Representative SEM images of the ceramic ML fractured discs. (a-c) The $50 \mu \mathrm{m} \mathrm{Al}_{2} \mathrm{O}_{3}$ treated group, and (d-f) the $50 \mu \mathrm{m}$ glass microbead-treated group.

\section{Discussion}

In the present study, we evaluated the BFSs of three highly translucent monolithic zirconia ceramics after subjecting them to different mechanical surface treatment protocols. Previous studies have demonstrated that sandblasting with aluminum oxide particles at $0.2 \mathrm{MPa}$ improved the BFSs of both conventional and high-translucent 3Y-TZP zirconia ceramics [34-36]. In our study, a similar result was observed for the DB high-translucent zirconia ceramic, which showed an increased flexural strength following air abrasion with both aluminum oxide and glass microbeads. However, we found that air abrasion decreased the BFS values for both DC and ML zirconia ceramics. Thus, the null hypothesis was rejected since it was found that the BFS was affected by the use of aluminum oxide or glass microbead air abrasion surface treatments.

The flexural strength of dental ceramics can be determined using 4-point and 3-point bending tests or a BFS test [37]. However, it should be noted that the fabrication of samples for uniaxial flexure testing methods can produce defects or flaws within the edges of samples, which can result in great variations in their resulting strength values when subjected to a load [35]. In contrast, the BFS test is advantageous for preventing premature failures from such flaws or cracks because these defective areas are not subjected directly to the load [38]. Moreover, strength tests using multiaxial loading could mimic the loading during 
the mastication process and so could be considered beneficial for examining the relevant mechanical properties of brittle dental materials [39]. Thus, the BFS test was employed for the purpose of this study. Previously, BFS tests have been carried out using different types of load configurations, such as ball on three balls, ball-on-ring, ring-on-ring, and piston-on-three-ball biaxial loadings [40,41]. For the piston-on-three-ball test, the load is applied by a piston at the center of the disc-shaped sample, which is supported by three metallic balls [31,37]. Although the piston-on-three-ball test can produce a non-uniform stress distribution under the piston, the strain will be increased to a greater degree than what is expected within the sample [42], and this is the only test that has been selected by the International Organization for Standardization (ISO 6782) for testing the BFS of dental ceramic materials [31]. Therefore, the piston-on-three-ball BFS test was implemented for the purpose of this study.

Air abrasion by alumina particles is known to promote a transformation toughening mechanism within the zirconia, in which the tetragonal to monoclinic phase transformation is accompanied by a volumetric expansion that limits the propagation of the initiated cracks $[6,37,43]$. This transformation toughening mechanism releases a residual compressive stress on the surface, which results in an increase in the fracture toughness and the BFS of the high-translucent 3Y-TZP material [44,45]. This could explain the high BFS values observed for the DB ceramic when subjected to airborne particle abrasion with either $50 \mu \mathrm{m}$ aluminum oxide or $50 \mu \mathrm{m}$ glass microbeads. Similar to our findings, a previous study evaluated the effects of different surface treatments, including surface abrasion with $50 \mu \mathrm{m}$ alumina particles, and concluded that such treatment methods increased the BFSs of conventional and high-translucent 3Y-TZP zirconia [34,35]. In contrast, reduced BFS values were observed for both 5Y-TZP DC and ML zirconia ceramics when the surfaces were treated with either aluminum oxide or glass microbeads. These results were in agreement with a previous study that reported a negative correlation between the BFS and the translucency of zirconia [37]. It should also be noted here that transformation of the tetragonal phase to the monoclinic phase within zirconia is highly dependent on the yttria content and the ceramic microstructure [46]. Thus, the increased yttria content of the 5Y-TZP ceramics resulted in a lower transformability of the tetragonal phase and hence a reduced release of compressive stresses and a decreased flexural strength [44,46]. In addition, the decreased strength was attributed to the lack of transformation toughening with an increased content of the cubic phase in these high-translucent zirconia ceramics [9]. Furthermore, it was previously reported that the mechanical stress caused by airborne particle abrasion could promote rhombohedral phase transformation in high-translucent zirconia, thereby resulting in lower mechanical properties [47]. A recent study also evaluated the effects of the alumina particle size on the release of residual compressive stresses from conventional and hightranslucent 5Y-ZP zirconia ceramics, and as a result, the use of $110 \mu \mathrm{m}$ aluminum oxide particles was suggested to treat the 3Y-TZP zirconia surface, while a particle size of only $25 \mu \mathrm{m}$ was suggested for 5Y-ZP zirconia ceramics [48].

Fractography allows for the accurate examination of fractured surfaces that contain microscopic features in which the direction of crack propagation is pointing toward the fracture origin site [49]. The qualitative fractography technique used in this study involves a description of the microscopic surface and the subsurface fracture features that indicate the crack origin site and the direction of crack propagation within each ceramic material. Various characteristic ceramic fracture features, such as hackles, twist hackles, fracture origins, arrest lines, and compression curls, were evident in the tested translucent zirconia fractured discs. When the maximum velocity of the crack is reached during crack propagation, a secondary crack hackle line is formed, and this line runs parallel to the direction of crack propagation and perpendicular to the crack origin site [33]. Twist hackles separate portions of the crack surface in which they rotate from the principal crack plane as a result of twisting in the principal tension axis [33]. Another characteristic feature is an arrest line, in which a well-defined sharp line occurs when the crack changes its direction while propagating, and this could be helpful in indicating the failure origin [50]. When the discs 
were loaded for flexural testing, a crack was initiated and propagated perpendicular to the tensile surface; this represents the crack origin site. As the crack propagates, it approaches the compression side of the sample and slows down, causing a compression curl to form, which is a common feature in ceramic failure and indicates the end of the fracture [50]. The presence of a compression curl is an important feature, since it indicates that the sample possessed a bending component when loaded [33]. It should be noted here that the fracture origin is usually located on the side opposite to that of the compression curl $[33,50]$.

We found that the DB sample exhibited multiple secondary cracks that likely led to shattering of the ceramic disc into multiple fractured pieces of varying sizes and the loss of smaller fragments of ceramics. For the DB sample, the resulting surface and subsurface porosities promoted crack initiation in these areas, and progress in multiple planes was frequently observed wherein secondary cracks were also present. Furthermore, in the case of the ML sample, a smooth fracture surface with clear fracture lines was generally observed.

Thus, based on the results of this study, the use of $50 \mu \mathrm{m}$ aluminum oxide particles for air abrasion at $0.2 \mathrm{MPa}$ pressure could be recommended for the surface treatment of high-translucent 3Y-TZP zirconia ceramics. In the case of 5Y-ZP ceramics, the use of $50 \mu \mathrm{m}$ glass microbeads for surface treatment negatively affected the BFS values, and so a smaller particle size should be considered in further studies.

The limitations of the current study include the fact that we concentrated on the type of air abrasion particles, while all other parameters were maintained constant. A limitation of the methodology used in this research is that the samples were machined, leaving microgrooves that could affect the transformation at the surface, and this could impact durability and strength of zirconia. Moreover, the effect of aging was not examined. Future studies should therefore investigate additional parameters, such as different air abrasion pressures and particle sizes.

\section{Conclusions}

Within the limitations of this study, it could be concluded that the air abrasion of a $3 \mathrm{~mol} \%$ yttria-stabilized tetragonal zirconia polycrystalline (3Y-TZP) translucent zirconia surface with $50 \mu \mathrm{m} \mathrm{Al} \mathrm{O}_{3}$ particles at a pressure of 2 bar resulted in the highest BFS values. In addition, the BFS of the tested 5Y-ZP ultra-translucent zirconia ceramic was negatively affected when air abrasion was carried out using either $50 \mu \mathrm{m} \mathrm{Al} \mathrm{Al}_{2} \mathrm{O}_{3}$ particles or $50 \mu \mathrm{m}$ glass microbeads. Smaller particle size should be considered in future research.

Author Contributions: Conceptualization, R.A., H.A. and A.M.; methodology, R.A., H.A. and A.E.; software, H.A. and R.A.; validation, R.A. and A.M.; formal analysis, R.A. and A.E.; investigation, R.A., H.A. and A.E.; resources, R.A.; data curation, R.A., H.A. and A.M.; writing-original draft preparation, R.A. and H.A.; writing-review and editing, R.A.; supervision, H.A., A.M. and A.E.; project administration, R.A.; funding acquisition, R.A. All authors have read and agreed to the published version of the manuscript.

Funding: The authors would like to thank the Deanship of Scientific Research at King Saud University, Riyadh, Saudi Arabia, for the funding and support during the completion of this study.

Institutional Review Board Statement: Not applicable.

Informed Consent Statement: Not applicable.

Data Availability Statement: Data sharing is not applicable to this article.

Acknowledgments: This study was registered and approved by the College of Dentistry Research Center (registration number: PR 0098). This manuscript is part of a DScD dissertation.

Conflicts of Interest: There are no known conflicts of interest associated with this study, and there has been no significant financial interest in any company or any products mentioned in this manuscript that could have influenced the outcome. 


\section{References}

1. Yoshida, K. Influence of alumina air-abrasion for highly translucent partially stabilized zirconia on flexural strength, surface properties, and bond strength of resin cement. J. Appl. Oral Sci. 2020, 28, e20190371. [CrossRef]

2. Zhang, X.; Liang, W.; Jiang, F.; Wang, Z.; Zhao, J.; Zhou, C.; Wu, J. Effects of air-abrasion pressure on mechanical and bonding properties of translucent zirconia. Clin. Oral Investig. 2020, 25, 1979-1988. [CrossRef]

3. Rinke, S.; Fischer, C. Range of indications for translucent zirconia modifications: Clinical and technical aspects. Quintessence Int 2013, 44, 557-566. [CrossRef]

4. Zhang, Y.; Lawn, B. Novel Zirconia Materials in Dentistry. J. Dent. Res. 2017, 97, 140-147. [CrossRef] [PubMed]

5. Tong, H.; Tanaka, C.B.; Kaiser, M.R.; Zhang, Y. Characterization of three commercial Y-TZP ceramics produced for their high translucency. Ceram. Int. 2016, 42, 1077-1085. [CrossRef] [PubMed]

6. Kwon, S.J.; Lawson, N.C.; McLaren, E.E.; Nejat, A.H.; Burgess, J.O. Comparison of the mechanical properties of translucent zirconia and lithium disilicate. J. Prosthet. Dent. 2018, 120, 132-137. [CrossRef]

7. Güth, J.F.; Stawarczyk, B.; Edelhoff, D.; Liebermann, A. Zirconia and its novel compositions: What do clinicians need to know? Quintessence Int. 2019, 50, 512-520.

8. Zhang, F.; Inokoshi, M.; Batuk, M.; Hadermann, J.; Naert, I.; van Meerbeek, B.; Vleugels, J. Strength, toughness and aging stability of highly-translucent Y-TZP ceramics for dental restorations. Dent. Mater. 2016, 32, e327-e337. [CrossRef] [PubMed]

9. Zhang, Y. Making yttria-stabilized tetragonal zirconia translucent. Dent. Mater. 2014, 30, 1195-1203. [CrossRef] [PubMed]

10. Harada, K.; Raigrodski, A.J.; Chung, K.-H.; Flinn, B.D.; Dogan, S.; Mancl, L.A. A comparative evaluation of the translucency of zirconias and lithium disilicate for monolithic restorations. J. Prosthet. Dent. 2016, 116, 257-263. [CrossRef]

11. Inokoshi, M.; de Munck, J.; Minakuchi, S.; van Meerbeek, B. Meta-analysis of Bonding Effectiveness to Zirconia Ceramics. J. Dent. Res. 2014, 93, 329-334. [CrossRef]

12. Mao, L.; Kaizer, M.; Zhao, M.; Guo, B.; Song, Y.; Zhang, Y. Graded Ultra-Translucent Zirconia (5Y-PSZ) for Strength and Functionalities. J. Dent. Res. 2018, 97, 1222-1228. [CrossRef]

13. Nobuaki, A.; Keiichi, Y.; Takashi, S. Effects of air abrasion with alumina or glass beads on surface characteristics of CAD/CAM composite materials and the bond strength of resin cements. J. Appl. Oral Sci. 2015, 23, 629-636. [CrossRef]

14. Zhang, Y.; Lawn, B.R.; Malament, K.A.; van Thompson, P.; Rekow, E.D. Damage accumulation and fatigue life of particle-abraded ceramics. Int. J. Prosthodont. 2007, 19, 442-448.

15. San, S.; Phyo, M.; Takagaki, T.; Kham, S. Effects of alumina-blasting pressure on the bonding to super/ultra-translucent zirconia. Dent. Mater. 2019, 35, 730-739.

16. Inokoshi, M.; Shimizu, H.; Nozaki, K.; Takagaki, T.; Yoshihara, K.; Nagaoka, N.; Zhang, F.; Vleugels, J.; van Meerbeek, B.; Minakuchi, S. Crystallographic and morphological analysis of sandblasted highly translucent dental zirconia. Dent. Mater. 2018, 34, 508-518. [CrossRef]

17. Passos, S.P.; Linke, B.; Major, P.W.; Nychka, J.A. The effect of air-abrasion and heat treatment on the fracture behavior of Y-TZP. Dent. Mater. 2015, 31, 1011-1021. [CrossRef]

18. Amaral, M.; Valandro, L.F.; Bottino, M.A.; Souza, R.O.A. Low-temperature degradation of a Y-TZP ceramic after surface treatments. J. Biomed. Mater. Res. Part B Appl. Biomater. 2013, 101, 1387-1392. [CrossRef]

19. Papanagiotou, H.P.; Morgano, S.M.; Giordano, R.A.; Pober, R. In vitro evaluation of low-temperature aging effects and finishing procedures on the flexural strength and structural stability of Y-TZP dental ceramics. J. Prosthet. Dent. 2006, 96, 154-164. [CrossRef]

20. Guazzato, M.; Quach, L.; Albakry, M.; Swain, M. Influence of surface and heat treatments on the flexural strength of Y-TZP dental ceramic. J. Dent. 2005, 33, 9-18. [CrossRef] [PubMed]

21. Zhang, Y.; Lawn, B.R.; Rekow, E.D.; Thompson, V.P. Effect of sandblasting on the long-term performance of dental ceramics. J. Biomed. Mater. Res. 2004, 71B, 381-386. [CrossRef]

22. Guazzato, M.; Albakry, M.; Quach, L.; Swain, M.V. Influence of surface and heat treatments on the flexural strength of a glass-infiltrated alumina/zirconia-reinforced dental ceramic. Dent. Mater. 2005, 21, 454-463. [CrossRef]

23. Uo, M.; Sjögren, G.; Sundh, A.; Goto, M.; Watari, F.; Bergman, M. Effect of Surface Condition of Dental Zirconia Ceramic (Denzir) on Bonding. Dent. Mater. J. 2006, 25, 626-631. [CrossRef]

24. McLaren, E.A.; Lawson, N.; Choi, J.; Kang, J.; Trujillo, C. New High-Translucent Cubic-Phase-Containing Zirconia: Clinical and Laboratory Considerations and the Effect of Air Abrasion on Strength. Compend. Contin. Educ. Dent. 2017, 38, e13-e16. [PubMed]

25. Coelho, C.M.P.; Rubo, J.H.; Pegoraro, L.F. Tensile bond strength of a resinous cement to a nickel-chromium alloy modified with five surface treatments. J. Prosthet. Dent. 1996, 76, 246-249. [CrossRef]

26. Nikaido, T.; Kataumi, M.; Burrow, M.F.; Inokoshi, S.; Yamada, T.; Takatsu, T. Bond strengths of resin to enamel and dentin treated with low-pressure air abrasion. Oper. Dent. 1996, 21, 218-224. [PubMed]

27. Martins, A.R.M.; Gotti, V.B.; Shimano, M.; Borges, G.; Gonçalves, L.D.S. Improving adhesion between luting cement and zirconia-based ceramic with an alternative surface treatment. Braz. Oral Res. 2015, 29, 54. [CrossRef] [PubMed]

28. Sen, N.; Us, Y.O. Mechanical and optical properties of monolithic CAD-CAM restorative materials. J. Prosthet. Dent. 2018, 119, 593-599. [CrossRef]

29. Okutan, Y.; Yucel, M.T.; Gezer, T.; Donmez, M.B. Effect of airborne particle abrasion and sintering order on the surface roughness and shear bond strength between Y-TZP ceramic and resin cement. Dent. Mater. J. 2019, 38, 241-249. [CrossRef] 
30. Martins, S.B.; Trindade, F.Z.; Góes, M.S.; Adabo, G.L.; Dovigo, L.N.; Fonseca, R.G. Does airborne-particle abrasion before, rather than after, zirconia sintering lead to higher mechanical strength even under aging challenge? J. Prosthet. Dent. 2020, 123, 155-162. [CrossRef]

31. International Organization for Standardization. ISO 6872: Dentistry-Ceramic Materials; ISO: Geneva, Switzerland, 2008.

32. Quinn, G.D. Fractography of Ceramics and Glasses (Special Publication 960-16); NIST-National Institute of Standards and Technology: Gaithersburg, MD, USA, 2007; Chapter 5; pp. 1-78.

33. Quinn, G.D. A NIST Recommended Practice Guide: Fractography of Ceramics and Glasses; Special Publication960-16e2; National Institute of Standardsand Technology: Washington, DC, USA, 2016. Available online: http://nvlpubs.nist.gov/nistpubs/ specialpublications/NIST.SP.960-16e2.pdf (accessed on 22 December 2021).

34. Moqbel, N.M.; Al-Akhali, M.; Wille, S.; Kern, M. Influence of Aging on Biaxial Flexural Strength and Hardness of Translucent 3Y-TZP. Materials 2019, 13, 27. [CrossRef] [PubMed]

35. Souza, R.O.A.; Valandro, L.F.; Melo, R.M.; Machado, J.P.B.; Bottino, M.A.; Özcan, M. Air-particle abrasion on zirconia ceramic using different protocols: Effects on biaxial flexural strength after cyclic loading, phase transformation and surface topography. $J$. Mechan. Behav. Biomed. Mater. 2013, 26, 155-163. [CrossRef] [PubMed]

36. Okada, M.; Taketa, H.; Torii, Y.; Irie, M.; Matsumoto, T. Optimal sandblasting conditions for conventional-type yttria-stabilized tetragonal zirconia polycrystals. Dent. Mater. 2018, 35, 169-175. [CrossRef]

37. Reyes, A.R.; Dennison, J.B.; Powers, J.M.; Sierraalta, M.; Yaman, P. Translucency and flexural strength of translucent zirconia ceramics. J. Prosthet. Dent. 2021, in press.

38. Börger, A.; Supancic, P.; Danzer, R. The ball on three balls test for strength testing of brittle discs: Stress distribution in the disc. J. Eur. Ceram. Soc. 2002, 22, 1425-1436. [CrossRef]

39. Ban, S.; Anusavice, K. Influence of Test Method on Failure Stress of Brittle Dental Materials. J. Dent. Res. 1990, 69, 1791-1799. [CrossRef]

40. Zeng, K.; Odén, A.; Rowcliffe, D. Flexure tests on dental ceramics. Int. J. Prosthodont. 1996, 9, 434-439.

41. Morrell, R. Biaxial flexural strength testing of ceramic materials. In A National Measurement Good Practice Guide; No. 12; NPL: Teddigton, UK, 2007.

42. Choi, B.-J.; Yoon, S.; Im, Y.-W.; Lee, J.-H.; Jung, H.-J.; Lee, H.-H. Uniaxial/biaxial flexure strengths and elastic properties of resin-composite block materials for CAD/CAM. Dent. Mater. 2018, 35, 389-401. [CrossRef]

43. Kelly, J.R.; Denry, I. Stabilized zirconia as a structural ceramic: An overview. Dent. Mater. 2008, 24, 289-298. [CrossRef]

44. Inokoshi, M.; Shimizubata, M.; Nozaki, K.; Takagaki, T.; Yoshihara, K.; Minakuchi, S.; Vleugels, J.; van Meerbeek, B.; Zhang, F. Impact of sandblasting on the flexural strength of highly translucent zirconia. J. Mech. Behav. Biomed. Mater. 2020, 115, 104268. [CrossRef]

45. Hjerppe, J.; Närhi, T.O.; Vallittu, P.K.; Lassila, L.V. Surface roughness and the flexural and bend strength of zirconia after different surface treatments. J. Prosthet. Dent. 2016, 116, 577-583. [CrossRef] [PubMed]

46. Zhang, F.; van Meerbeek, B.; Vleugels, J. Importance of tetragonal phase in high-translucent partially stabilized zirconia for dental restorations. Dent. Mater. 2020, 36, 491-500. [CrossRef]

47. Maruo, Y.; Yoshihara, K.; Irie, M.; Nishigawa, G.; Nagaoka, N.; Matsumoto, T.; Minagi, S. Flexural properties, bond ability, and crystallographic phase of highly translucent multi-layered zirconia. J. Appl. Biomater. Funct. Mater. 2020, 18, 2-5. [CrossRef]

48. Kim, H.-K.; Ahn, B. Effect of $\mathrm{Al}_{2} \mathrm{O}_{3}$ Sandblasting Particle Size on the Surface Topography and Residual Compressive Stresses of Three Different Dental Zirconia Grades. Materials 2021, 14, 610. [CrossRef] [PubMed]

49. Scherrer, S.S.; Lohbauer, U.; Della Bona, A.; Vichi, A.; Tholey, M.J.; Kelly, J.R.; van Noort, R.; Cesar, P.F. ADM guidance-Ceramics: Guidance to the use of fractography in failure analysis of brittle materials. Dent. Mater. 2017, 33, 599-620. [CrossRef]

50. Scherrer, S.S.; Quinn, J.B.; Quinn, G.D.; Kelly, J.R. Failure analysis of ceramic clinical cases using qualitative fractography. Int. J. Prosthodont. 2006, 19, 185-192. [PubMed] 